\title{
Desenvolvimento Relativo dos Tecidos Ósseo, Muscular e Adiposo dos Cortes da Carcaça de Cordeiros Santa Inês
}

\author{
Cristiane Leal dos Santos ${ }^{1}$, Juan Ramon Olalquiaga Pérez ${ }^{2}$, Joel Augusto Muniz ${ }^{3}$, \\ Luciana Castro Geraseev', Edson Ramos Siqueira ${ }^{4}$
}

\begin{abstract}
RESUMO - O trabalho foi conduzido no Setor de Ovinocultura do Departamento de Zootecnia da UFLA, em Lavras, com o objetivo de estudar o crescimento alométrico dos tecidos ósseo, muscular e adiposo dos cortes comerciais em cordeiros. Foram utilizados 24 cordeiros machos inteiros da raça Santa Inês. Os animais foram submetidos a regime de confinamento e receberam alimentação ad libitum. O abate ocorreu quando os animais atingiram os pesos vivos de 15,25,35 e $45 \mathrm{~kg}$. Após a carcaça ter sido limpa e resfriada, foram obtidos os cortes comerciais a partir da meia carcaça esquerda. A quantidade dos diferentes tecidos foram obtidos por intermédio da dissecação de perna, lombo, costeleta, costela/ fralda e paleta. O estudo do desenvolvimento relativo da composição tecidual foi feito por meio do modelo de HUXLEY (1932). Constatou-se crescimento heterogônico negativo ( b < 1) para o tecido ósseo e heterogônico positivo (b > 1) para o tecido adiposo de todos os cortes. Quanto ao tipo de crescimento do tecido muscular da costela/fralda e paleta, foi verificado crescimento isogônico $(b=1)$ deste tecido em relação aos cortes.
\end{abstract}

Palavras-chave: alometria, Santa Inês, tecido adiposo, tecido muscular, tecido ósseo

\section{Relative Development of the Bone, Muscular and Fat Tissues of Joints of the Carcass of Santa Ines Lambs}

\begin{abstract}
An experiment was carried out at the Sheep Production Sector of Federal University of Lavras to study the allometric growth of bone, muscular and fat tissues of commercial joints in lambs. Twenty-four Santa Ines lambs were used. The animals were kept confined in individual pens and fed ad libitum. The animals were slaughtered when they reached the target live weight of 15,25 , 35 and $45 \mathrm{~kg}$. After the carcass had been dressed and chilled, the commercial joints were obtained from the left half part. The amount of the different tissues were got through the dissection of the leg, lion, rib, breast and shoulder. The allometric study was carried out using the model developed by HUXLEY(1932). The allometric coefficient of bone was lower than 1, the coefficient for the fat tissue was higher than 1 in all joints, and the muscular tissue in the ribs and shoulder were analysed for these joints, the coefficient was not different from 1 .
\end{abstract}

Key Words: allometric, Santa Ines, tissue bone, tissue fat, tissue muscle

\section{Introdução}

O crescimento do cordeiro desde o nascimento, em condições ambientais adequadas, é descrito por uma curva sigmóide, havendo aceleração da sua velocidade até que a puberdade seja atingida, diminuindo gradativamente, então, até a maturidade (PRESCOTT, 1982). Em relação à carcaça, os constituintes básicos são os músculos, os ossos e a gordura. Cada tecido terá um impulso de desenvolvimento em uma fase diferente da vida do animal. O tecido ósseo apresenta crescimento mais precoce; o muscular, intermediário; e o adiposo, mais tardio, de acordo com a maturidade fisiológica (HAMMOND 1960; 1965).
As curvas de crescimentos destes tecidos (ósseo, muscular e adiposo), em função do aumento do peso dos animais, apresentam padrões distintos. Os músculos têm crescimento mais acelerado em animais mais jovens e a gordura apresenta crescimento mais acentuado em animais mais maduros, sendo que os ossos apresentam menor velocidade de crescimento que os demais componentes. Ao se analisar o desenvolvimento do animal, devem-se, portanto, considerar os aspectos de desenvolvimento dos tecidos em conjunto (relação osso x músculo x gordura) e as características de deposição de gordura nas diferentes partes do corpo (SAINZ,1996).

O crescimento relativo dos tecidos tem a seguinte

\footnotetext{
1 Doutorando do Curso de Zootecnia da UFLA, Caixa Postal, 37-37200-000-Lavras-MG. E.mail: crisleal@ufla.br

2 Professor PhD do Departamento de Zootecnia, UFLA, Caixa Postal, 37 - CEP: 37200-000 - Lavras, MG. E.mail: jroperez@ufla.br

3 Professor DSc do Departamento de Ciências Exatas, UFLA, Caixa Postal, 37 - CEP: 37200-000 - Lavras, MG. E.mail: joamuniz@ufla.br

4 Professor DSc do Departamento da Faculdade de Medicina Veterinária, UNESP - Botucatu. E.mail: e.r.siqueira@fca.unesp.br
} 
ordem: osso, músculo e gordura (pélvico- renal e subcutânea), sendo que o estado de engorduramento aumenta com a idade dos cordeiros (WOOD et al., 1980). O aumento da maturidade dos animais leva a acréscimo da proporção de gordura, diminuição da proporção de ossos e pouca mudança na proporção de músculo na carcaça (ROBELIN et al., 1977; TAYLOR, 1985; THÉRIEZ et al., 1981). As modificações destas relações são de grande importância na determinação da qualidade das carcaças.

A maioria dos trabalhos é realizada para verificar o crescimento alométrico dos tecidos ósseo, muscular e adiposo em relação ao peso da carcaça, no entanto, informações a respeito de como esses tecidos crescem em relação à evolução do peso de determinados cortes comerciais da carcaça de ovinos são raros e inexistentes em animais da Raça Santa Inês.

Os ovinos da raça Santa Inês são animais que apresentam maiores velocidades de crescimento em relação a outros ovinos deslanados (SIQUEIRA, 1990) e, segundo CORRADELLO (1988), a raça é muito promissora para a produção de carne, por apresentar precodidade, alto rendimento de carcaça e grande resistência a doenças ambientais.

O objetivo deste trabalho foi realizar uma descrição quantitativa adequada do crescimento relativo dos tecidos ósseo, muscular e adiposo dos cortes comerciais, perna, lombo, costeleta (carrê), costela/ fralda e paleta, de cordeiros da raça Santa Inês em crescimento desde os 15 aos $45 \mathrm{~kg}$ de peso vivo.

\section{Material e Métodos}

O experimento foi desenvolvido no Setor de Ovinocultura, Departamento de Zootecnia da Universidade Federal de Lavras, Minas Gerais. Foram utilizados 24 cordeiros machos inteiros com peso inicial de $15 \mathrm{~kg}$ da raça Santa Inês, mantidos sob regime de confinamento, em gaiolas individuais. A dieta utilizada foi constituída de feno triturado de coastcross (Cynodon dactylon), farelo de soja (Glicine max L.), grão de milho (Zea mays L.), calcário calcítico, suplemento mineral e vitamínico, calculada com base nas exigências nutricionais estabelecidas pelo ARC (1980), para ganho de peso diário esperado de $300 \mathrm{~g}$.

Os cordeiros foram sorteados para serem sacrificados com diferentes pesos: $15,25,35$ e $45 \mathrm{~kg}$ de peso vivo, com aproximadamente as respectivas idades de 50, 100, 140 e 190 dias. O abate foi feito por meio de um corte na artéria carótida e nas veias jugulares, com coleta e pesagem do sangue e posterior evisceração, depois de retirada a pele. Após a evisceração e retirada da cabeça, dos pés e da cauda, obteve-se a carcaça, a qual foi pesada para obtenção do peso da carcaça.

A carcaça quente foi levada à câmara fria, à $2^{\circ} \mathrm{C}$, por um período de 24 horas. A carcaça foi mantida pendurada pela articulação tarso metatarsiana em ganchos próprios, com distanciamento de $17 \mathrm{~cm}$. Após esse período, procedeu-se à retirada do pescoço e, em seguida, mediante corte longitudinal, obtiveram-se metades aproximadamente simétricas.

A meia carcaça esquerda foi dividida em cinco cortes comerciais: perna, lombo, costeleta (carrê), costela/fralda e paleta (Figura 1), que tiveram a seguinte base anatômica:

Perna: compreendeu a região sacral e os seguintes seguimentos anatômicos do membro pélvico: cíngulo pélvico e perna. Seccionou-se ao nível da articulação da última vértebra lombar e primeira sacral e ao nível da posição mediana dos ossos do tarso. Obteve-se por um corte transversal, que passou entre a articulação da última vértebra lombar e a primeira sacral, seccionando o ligamento superespinhoso lombo sacro, ligamento interespinhoso e ligamento longitudinal ventral e dorsal, terminando aproximadamente na aponeurose, que une o músculo recto do abdome (M. rectus abdominis) com a porção carnosa do obliquo interno do abdômen (M. obliquus internus).

Lombo: a base óssea deste corte compreendeu da primeira à última vértebras) vértebra lombar (pode ter 6 ou 7). Foi feito um corte entre a última vértebra torácica e a primeira lombar e outro entre a última lombar e a primeira sacral.

Costeleta: compreende a região localizada entre a $1^{\mathrm{a}}$ a $12^{\mathrm{a}}$ vértebra torácica, junto com aproximadamente $1 / 3$ dorsal do corpo das costelas correspondentes.

Costela/Fralda : este corte compreendeu a região anatômica da parede abdominal e metade ventral da torácica. Sua base óssea foi metade correspondente do esterno cortado sagitalmente, a 2/3 ventral das oito primeiras costelas e $2 / 3$ ventral das cinco restantes. Obteve-se fazendo-se um corte aproximadamente paralelo à coluna vertebral, partindo desde a prega inguinal e acabando no cordão testicular. Termina no vértice da cartilagem do manubrio esternal ou na articulação da primeira costela com a primeira esternebra.

Paleta: as regiões anatômicas que compreenderam este corte foram o cíngulo escapular e braço antebraço. A base óssea foi formada pela escápula, úmero, rádio e ossos do carpo. Obteve-se mediante secção da 
Rev. bras. zootec.

região axilar, dos músculos que unem a escápula e o úmero na parte ventral do tórax. Depois, contornou-se a escápula, seccionando os músculos braquiocefálico, omo transversal, trapézio cervical e serrato cervical, pela parte superior, e trapézio torácico e romboides, pela parte posterior do tronco.

Os cortes foram pesados e acondicionados em sacos plásticos e mantidos no freezer a $-10^{\circ} \mathrm{C}$ até o momento da dissecação, ou seja, separação dos componentes teciduais (osso, músculo e gordura) de cada corte. Assim, foram obtidos proporção e crescimento relativo dos mesmos em cada corte, nos intervalos de pesos estudados.

O estudo do crescimento relativo foi realizado mediante o modelo da equação exponencial, $\mathbf{Y}=\mathbf{a} \mathbf{X}^{\mathbf{b}} \boldsymbol{\varepsilon} \mathbf{i}$, transformada logaritmicamente em um modelo linear, $\ln \mathbf{Y}=\ln \mathbf{a}+\mathbf{b} \ln \mathbf{X}+\ln \varepsilon \mathbf{i}(\mathrm{HUXLEY}, 1932)$

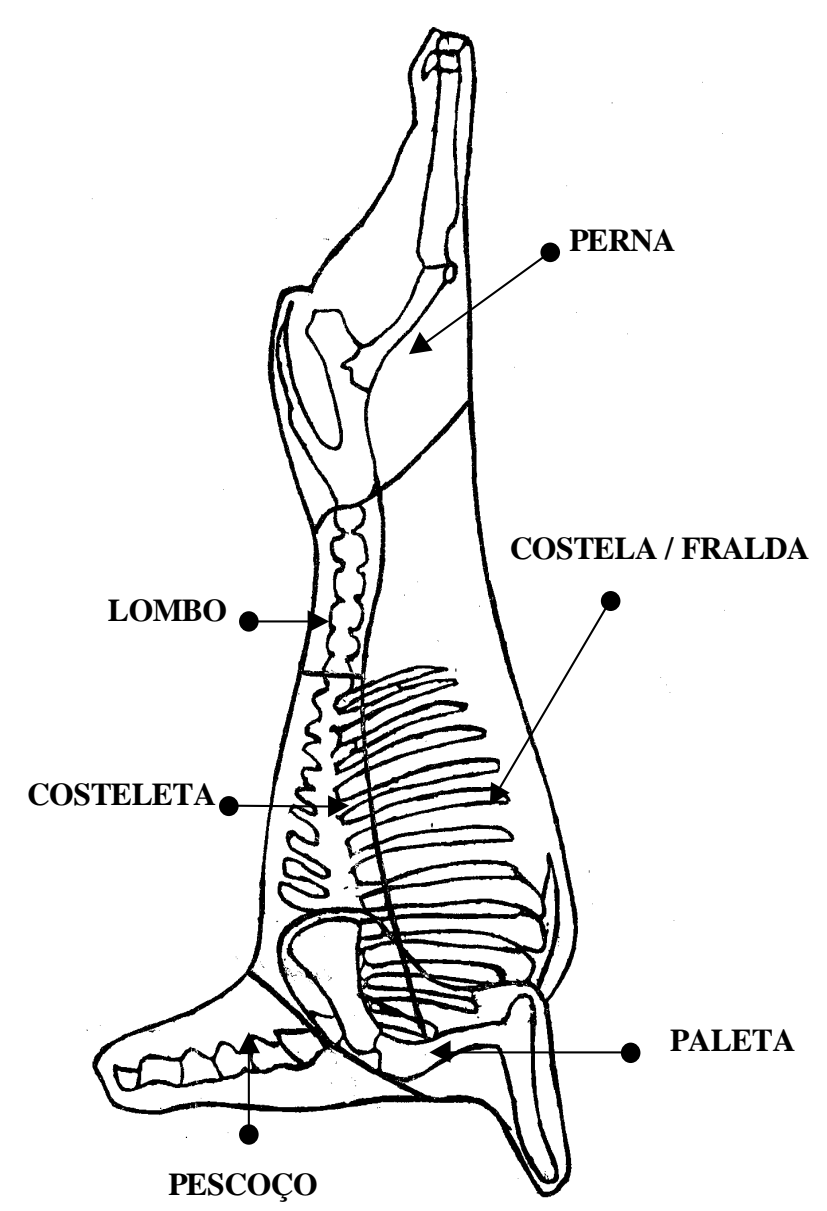

Figura 1 - Cortes efetuados na $1 / 2$ carcaça esquerda de cordeiros Santa Inês.

Figure 1 - Joints determined in $1 / 2$ left carcass of Santa Ines lambs. em que $\mathbf{Y}$ é o peso de cada componente tecidual (osso, músculo e gordura); $\mathbf{X}$, o peso de cada corte comercial (perna, lombo, costeleta, costela/fralda, paleta) a, a intercepção do logaritmo da regressão linear sobre $\mathbf{Y}$ e "b"; $\mathbf{b}$, o coeficiente de crescimento relativo ou coeficiente de alometria; $\boldsymbol{\varepsilon}$ i, o erro multiplicativo.

As análises para obtenção dos coeficientes alométricos foram realizadas por intermédio do SAS (1996). Para verificação da hipótese $b=1$, foi realizado o teste "t" (Student Newman Keuls) $(\alpha=0,05$ e $\mathrm{a}=0,01)$. Se $\mathrm{b}=1$, o crescimento foi denominado isogônico, indicando que as taxas de desenvolvimento de cada componente $(\mathrm{X})$ e do respectivo corte $(\mathrm{Y})$ foram semelhantes no intervalo de crescimento considerado. Quando $b \neq 1$, o crescimento foi chamado heterogônico, sendo positivo $(b>1)$, tecido de desenvolvimento tardio; ou negativo $(b<1)$, tecido de desenvolvimento precoce em relação ao desenvolvimento do corte.

\section{Resultados e Discussão}

Na Tabela 1, são apresentadas as equações de alometria para os componentes teciduais: osso, músculo e gordura de cada corte obtido na meia carcaça esquerda dos cordeiros Santa Inês. Os coeficientes de alometria do tecido ósseo de todos os cortes estudados, perna, lombo, costeletas, costela/fralda e paleta, indicam que o osso teve desenvolvimento precoce $(\mathrm{b}<1)$ em relação ao desenvolvimento dos cortes, concordando com a afirmação de ESMINGER et al. (1990) de que esse tecido se desenvolve mais rapidamente que o muscular e o adiposo.

Os coeficientes de determinação do tecido ósseo do lombo, das costeletas e costela/fralda, comparados com os demais coeficientes referentes a este mesmo tecido na perna e paleta, apresentaram valores menores, 67,$14 ; 72,47 ;$ e 70,26\%, o que é explicado pela anatomia dos cortes, os quais possuem maior estrutura óssea, o que leva a desvios no processo de dissecação, no entanto, com essas variações totais, o modelo proposto foi adequado aos pontos observados, uma vez que, com desvios pequenos, a maioria dos pontos ficou em consonância com o modelo, sempre em seu entorno.

O tecido muscular da perna e costeleta apresentou coeficiente de alometria diferente de $1(b \neq 1)$, caracterizando crescimento heterogônico positivo para esse componente tecidual $(b>1)$ (Figuras 2 e 3 , respectivamente), ou seja, o tecido muscular teve desenvolvimento relativo tardio em relação ao desenvolvimento relativo da perna e da costeleta . Para os 
Tabela 1 - Equações de alometria para os componentes teciduais , osso (O), músculo (M) e gordura (G) dos cortes da carcaça de cordeiros da raça Santa Inês, em relação ao peso do corte (PC), e verificação da diferença do coeficiente de alometria com a unidade e seu respectivo erro-padrão (Sd)

Table 1 - Allometry equations for the tissue component, bone (B), muscle $(M)$ and fat $(F)$ of the joints of the carcass of Santa Ines lambs, in relation to the weight of the joints (WJ), and verification of the difference of the allometry coefficient, with the unit and its respective standard error $(S d)$

\begin{tabular}{lccc}
\hline Cortes & Equação & Td & Teste $\mathrm{t}$ \\
Joints & Equation & $\mathrm{R}^{2}$ \\
& $\ln \mathrm{Y}=\ln \mathrm{a}+\mathrm{b} \ln \mathrm{X}$ & Ho: $\mathrm{b}=1$ & \\
\hline
\end{tabular}

Perna

Leg

\begin{tabular}{|c|c|c|c|c|}
\hline Osso & $\ln \mathrm{O}=-1,315+0,719 \ln \mathrm{PC}$ & 0,035 & $* *$ & 94,59 \\
\hline Bone & & & & \\
\hline Músculo & $\ln \mathrm{M}=-0,479+1,039 \ln \mathrm{PC}$ & 0,017 & $*$ & 99,33 \\
\hline Muscle & & & & \\
\hline $\begin{array}{l}\text { Gordura } \\
\text { Fat }\end{array}$ & $\ln \mathrm{G}=-2,345+1,458 \ln \mathrm{PC}$ & 0,097 & $* *$ & 90,65 \\
\hline
\end{tabular}

Lombo

Loin

\begin{tabular}{|c|c|c|c|c|}
\hline Osso & $\ln \mathrm{O}=-1,654+0,685 \ln \mathrm{PC}$ & 0,098 & $* *$ & 67,14 \\
\hline Bone & & & & \\
\hline Músculo & $\ln \mathrm{M}=-0,539+0,976 \ln \mathrm{PC}$ & 0,042 & n.s & 95,76 \\
\hline Muscle & & & & \\
\hline $\begin{array}{l}\text { Gordura } \\
\text { Fat }\end{array}$ & $\ln G=-1,459+1,725 \ln P C$ & 0,144 & $* *$ & 86,05 \\
\hline
\end{tabular}

Costeletas

Rib

\begin{tabular}{|c|c|c|c|c|}
\hline Osso & $\ln \mathrm{O}=-1,301+0,481 \ln \mathrm{PC}$ & 0,061 & $* *$ & 72,47 \\
\hline Bone & & & & \\
\hline Músculo & $\ln \mathrm{M}=-0,625+1,102 \ln \mathrm{PC}$ & 0,038 & $*$ & 97,97 \\
\hline $\begin{array}{l}\text { Muscle } \\
\text { Gordura } \\
\text { Fat }\end{array}$ & $\ln \mathrm{G}=-1,852+1,861 \ln \mathrm{PC}$ & 0,166 & $* *$ & 84,20 \\
\hline Fralda & & & & \\
\hline $\begin{array}{l}\text { Osso } \\
\text { Bone }\end{array}$ & $\ln \mathrm{O}=-1,666+0,498 \ln \mathrm{PC}$ & 0,068 & $* *$ & 70,26 \\
\hline $\begin{array}{l}\text { Músculo } \\
\text { Muscle }\end{array}$ & $\ln \mathrm{M}=-0,733+0,982 \ln \mathrm{PC}$ & 0,055 & n.s & 93,19 \\
\hline $\begin{array}{l}\text { Gordura } \\
\text { Fat }\end{array}$ & $\ln \mathrm{G}=-1,155+1,300 \ln \mathrm{PC}$ & 0,099 & $* *$ & 91,67 \\
\hline
\end{tabular}

Paleta

Shoulder

\begin{tabular}{|c|c|c|c|c|}
\hline Osso & $\ln \mathrm{O}=-1,463+0,733 \ln \mathrm{PC}$ & 0,072 & $* *$ & 89,79 \\
\hline Bone & & & & \\
\hline Músculo & $\ln \mathrm{M}=-0,512+1,028 \ln \mathrm{PC}$ & 0,022 & n.s & 98,94 \\
\hline $\begin{array}{l}\text { Muscle } \\
\text { Gordura }\end{array}$ & $\ln \mathrm{G}=-1,861+1,237 \ln \mathrm{PC}$ & 0,094 & $* *$ & 88,82 \\
\hline
\end{tabular}

* Significativo a $5 \%$ de probabilidade (Significant at $5 \%$ of probability).

** Significativo a $1 \%$ de probabilidade (Significant at $1 \%$ of probability).

demais cortes: lombo, costela/ fralda e paleta, o crescimento muscular acompanhou o desenvolvimento relativo do corte, apresentando crescimento isogônico (Figuras 4, 5 e 6, respectivamente). O tecido adiposo apresentou desenvolvimento tardio em todos os cortes, tendo crescimento heterogônico positivo (b > 1) em relação ao desenvolvimento de cada corte como um todo.

Com o avançar da idade e, conseqüentemente, aumento do peso, a quantidade de gordura eleva-se nas diferentes partes da carcaça, o que pode ser explicado por KOLB(1976) e HOOD e THORNTON 
Rev. bras. zootec.

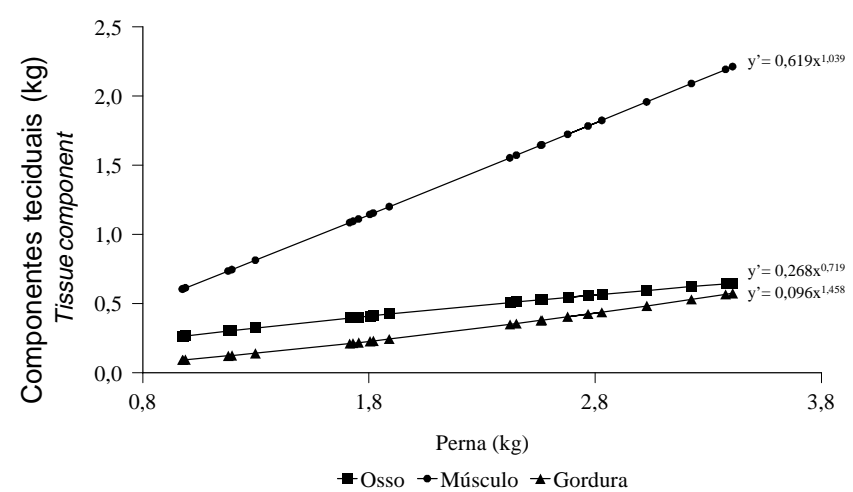

Figura 2 - Crescimento alométrico dos componentes teciduais, osso, músculo e gordura, da PERNA de cordeiros Santa Inês, em relação ao peso do corte.

Figure 2 - Alometric growth of the tissue component, bone, muscle and fat of the LEG, of Santa Ines lambs, in relation to joint weight.

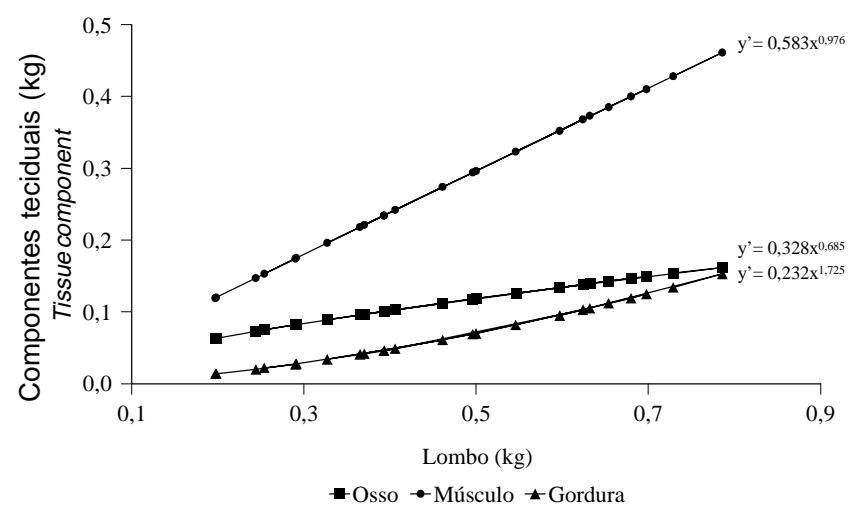

Figura 4 - Crescimento alométrico dos componentes teciduais, osso, músculo e gordura do LOMBO, de cordeiros Santa Inês, em relação ao peso do corte.

Figure 4-Alometric growth of the components, tissue, bone, muscle and fat of the LOIN, of Santa Ines lambs, in relation to joint weight.

(1979), citados por SIQUEIRA (1990), os quais constaram aumento do número de células adiposas, tomando-se por base a fase de crescimento compreendida entre 28 e $45 \mathrm{~kg}$ de peso vivo.

À medida que aumenta o peso de abate, eleva-se a quantidade de gordura na carcaça dos animais e, por intermédio de determinados cortes efetuados na mesma, é possível verificar de forma mais acentuada o cresci-

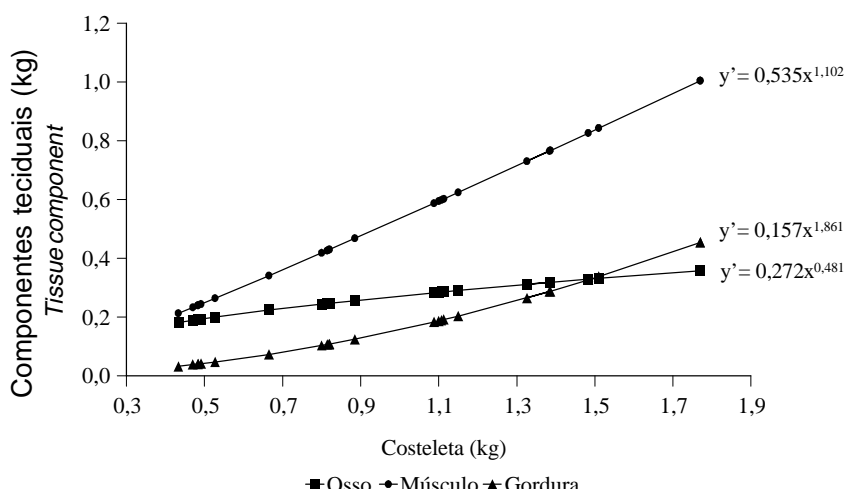

Figura 3 - Crescimento alométrico dos componentes teciduais, osso, músculo e gordura, da COSTELETA de cordeiros Santa Inês, em relação ao peso do corte.

Figure 3 - Alometric growth of the tissue component, bone, muscle and fat of the RIBS, of Santa Ines lambs, in relation to joint weight.

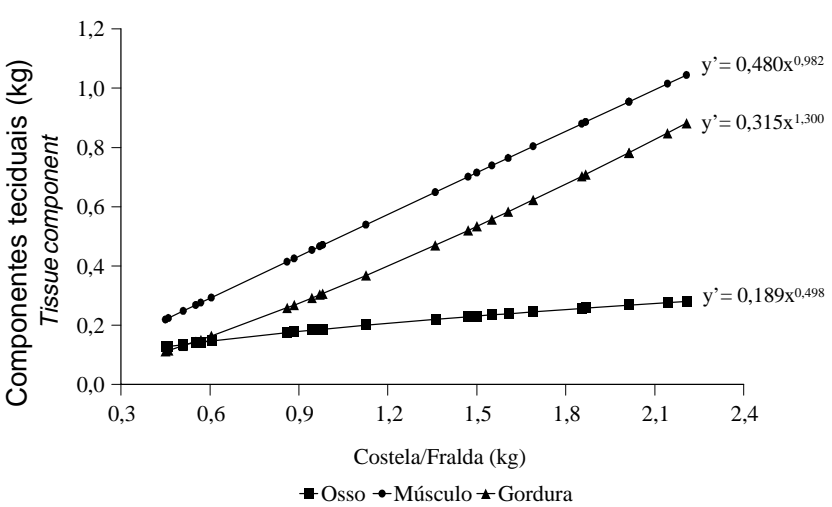

Figura 5 - Crescimento alométrico dos componentes teciduais, osso, músculo e gordura da COSTELA/ FRALDA de cordeiros Santa Inês, em relação ao peso do corte.

Figure 5 - Alometric growth of the component tissue, bone, muscle and fat of the BREAST of Santa Ines lambs, in relation to joint weight.

mento do tecido adiposo como no corte costela/fralda.

Os cordeiros abatidos entre 15 e $35 \mathrm{~kg}$ de peso vivo foram os que apresentaram cortes com as melhores deposição de gordura, levando em consideração que uma quantidade elevada deste componente significa qualidade de carne de caráter inferior.

Com o aumento da idade, a qualidade dos cortes fica comprometida, uma vez que as características 


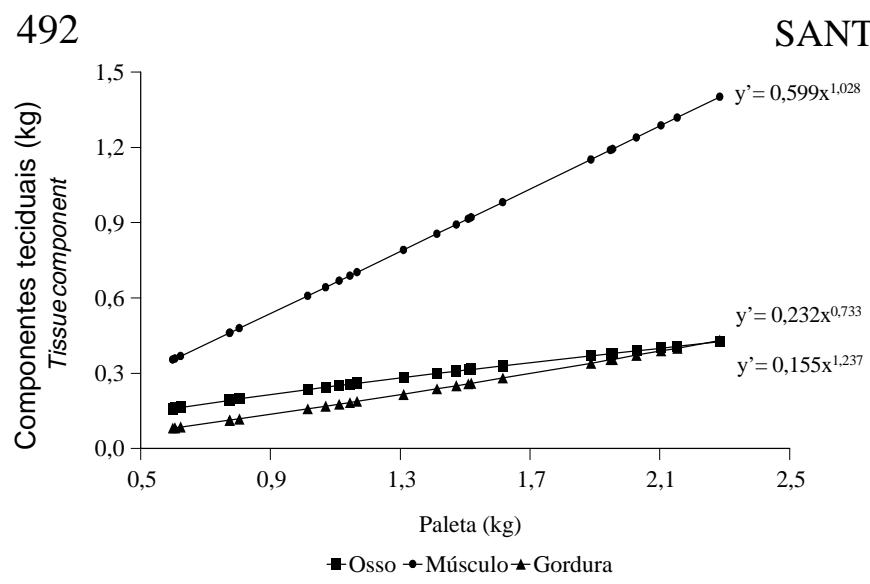

Figura 6 - Crescimento alométrico dos componentes teciduais, osso, músculo e gordura da PALETA, de cordeiros Santa Inês, em relação ao peso do corte.

Figure 6 - Alometric growth of the components tissue, bone, muscle and fat of the SHOULDER, of Santa Ines lambs, in relation to joint weight.

organolépticas se modificam com a idade do animal, havendo decréscimo da maciez, do sabor e da solubilidade de colágeno muscular.

\section{Conclusões}

Para atender as exigências do mercado consumidor atual, a faixa de peso de abate para que se obtenham cortes com adequadas deposições de gordura encontra-se entre 15 e $35 \mathrm{~kg}$ de peso vivo, uma vez que, acima deste peso, na maioria dos cortes estudados, o tecido adiposo apresentou crescimento heterogônico positivo.

\section{Referências Bibliográficas}

AGRICULTURAL RESEARCH COUNCIL - ARC. 1980. The nutrient requeriments os farm livestock. London. $351 \mathrm{p}$.

CORRADELLO, E.F.A.1988. Criação de ovinos: antiga e contínua atividade lucrativa. São Paulo: Ícone. 124p.

ESMINGER, M.E., OLDFIELD, J.E., HEINEMANN, W.W. 1990. Feeds and Nutrition. 2.ed., Califórnia. 1544p.

HAMMOND, J. 1960. Carne: Producción y tecnologia: conferencias, observaciones. Mesas redondas, s. 1. CAFADE. 160p .

HAMMOND, J.1965. Farm animal; their growth breeding and inheritance. London: E. Arnould. 322p.

HUXLEY, J.S. 1932. Problems of relative growth. London: Methuen. 577p.

PRESCOTT, J.H.D. 1982. Crecimiento y desarrollo de los corderos. In: HAPEZ, E.S.E. (Ed.) Crescimento e desarollo de los corderos.. Zaragoza: Acribia. p.35-369.

ROBELIN, J., THÉIRIEZ, M., ARNAL, M. et al. 1977. Évolution de la composition chimique des jeunes ageneause mâles jusquí a âge de 16 semaines. Anim. Zoot., 26:68-81.

SAINZ, R.D. Qualidade de carcaças e de carne de ovinos e caprinos. In: REUNIÃO ANUAL DA SOCIEDADE BRASILEIRA DE ZOOTECNIA, 33, 1996, Fortaleza. Anais... Fortaleza: SBZ, 1996. p.3-14.

SAS INSTITUTE. 1996. In: Procedures. Versão 6, v.1.3.ed. Cray.

SIQUEIRA, E.R. Estratégias de alimentação do rebanho e tópicos sobre produção de carne ovina. In: PRODUÇÃO DE OVINOS, 1990. Jaboticabal. Anais... Jaboticabal: FUNEP, 1990. p.157-171.

TAYLOR, C.S. 1985. Use of genetic size scaling in evaluation of animal growth. J. Anim. Sci., 61(2):119-143.

THÉIRIEZ, M., TISSIER, M., ROBELIN, J. 1980. The chemical composition of the intensively fed lamb. Anim. Prod., 32(1):29-37.

WOOD, J.D., MACFIE, H.J.H., POMEROY, R.W. et al. 1998. Carcass composition in four sheep breeds the importance of type of breed and staje of maturity. Anim. Prod., 30(31):135-152.

Recebido em: 24/05/00

Aceito em: 06/10/00 